Check for updates

Cite this: RSC Adv., 2017, 7, 47833

Received 16th August 2017

Accepted 26th September 2017

DOI: $10.1039 / \mathrm{c} 7 \mathrm{ra0} 0056 \mathrm{k}$

rsc.li/rsc-advances

\section{Oxidation behavior of silicon nitride fibers obtained from polycarbosilane fibers via electron beam irradiation curing}

\begin{abstract}
X. Sun, H. T. Liu (D)* and H. F. Cheng
Near-stoichiometric silicon nitride $\left(\mathrm{Si}_{3} \mathrm{~N}_{4}\right)$ fibers, which were successfully prepared from polycarbosilane fibers via electron beam irradiation curing, were heat-treated at elevated temperature for $2 \mathrm{~h}$ in the air atmosphere. The compositions and microstructures of silicon nitride fibers before and after heat treatment were investigated by XRD, XPS, NMR, SEM and TEM analyses. Tensile properties of the untreated and heat-treated fibers were also studied. The results show that the untreated fibers were mainly composed of amorphous silicon nitride and a few $\mathrm{Si}_{2} \mathrm{~N}_{2} \mathrm{O}$ phases. During the heat treatment process, the oxidation of the fibers from silicon nitride to silicon dioxide initiated at $1100{ }^{\circ} \mathrm{C}$. As the treatment temperature increased to $1400{ }^{\circ} \mathrm{C}$, an oxidation layer with a thickness of $\sim 2 \mu \mathrm{m}$ was formed on the fiber surface. Besides, when the treatment temperature was up to $1200{ }^{\circ} \mathrm{C}$, the strength retention of the fibers still was $50.29 \%$, which indicates that the fiber might possess a high serving life at a temperature lower than $1200^{\circ} \mathrm{C}$.
\end{abstract}

\section{Introduction}

Continuous silicon nitride $\left(\mathrm{Si}_{3} \mathrm{~N}_{4}\right)$ fibers are considered as one of the important ceramic fibers due to their ascendant properties, such as excellent mechanical properties, high oxidation resistance, superior electrical insulating property at elevated temperature and low dielectric constant. They can be regarded as one of the most suitable reinforcements for high-performance ceramic matrix composites (CMCs) employed at high temperatures..-5 Continuous silicon nitride ceramic fibers, as a type of silicon nitride materials, are optimal candidates for the reinforcement of wave-transparent ceramic matrix composites (CMCs) applied in radome materials. ${ }^{6}$

In the last two decades, several ceramic fibers, which are mainly composed of silicon and nitride, have been prepared by many researchers worldwide. For instance, Sinber fibers were produced by Japan Atomic Energy Research Institute, ${ }^{7} \mathrm{Si}-\mathrm{C}-\mathrm{N}$ fibers were created by Domaine University, ${ }^{8}$ and silicon nitride fibers (SNF) were developed by Dow Corning Corporation. ${ }^{9}$ Among these fibers, only SNF fibers can be employed in the applications that require the materials with wave-transparent properties and contain $3 \mathrm{wt} \%$ of carbon and can be treated as high-purity silicon nitride fibers. However, the SNF fibers, which are fabricated by pyrolysis of hydridopolysilazane (HPZ), have strong reactivity, which leads to diffusion reaction with the ceramic matrix. Therefore, in this work, in order to satisfy the application in radome materials, near-stoichiometric silicon

Science and Technology on Advanced Ceramic Fibers and Composites Laboratory, National University of Defense Technology, Changsha 410073, China. E-mail: htslht@163.com nitride ceramic fibers were prepared by pyrolysis of polycarbosilane (PCS) fibers via electron beam curing in the $\mathrm{NH}_{3}$ atmosphere. The PCS, which consists of a skeleton of alternate carbon and silicon atoms, is widely used as the precursor for preparation of silicon nitride ceramic materials, such as porous ceramics and ceramic fibers. ${ }^{10-14}$ Electron beam (EB) irradiation curing, other than thermal oxidation, can effectively reduce the oxygen content of the fiber and, sequentially, enhance the hightemperature performance of the fiber. ${ }^{15,16}$

Since $\mathrm{Si}_{3} \mathrm{~N}_{4}$ fibers are the backbone in load-bearing CMCs, their strength and strength retention throughout the service life are critical to the performance of CMCs. Therefore, it is essential to acquire a comprehensive knowledge of the microstructure and the tensile behavior of $\mathrm{Si}_{3} \mathrm{~N}_{4}$ fibers at elevated temperature in order to understand the degradation behavior and forecast the performance of CMCs at high temperatures. Moreover, the key thermal characteristic of $\mathrm{Si}_{3} \mathrm{~N}_{4}$ fibers is their oxidation resistance at high temperatures for a long time. ${ }^{17}$ Furthermore, to the best of our knowledge, the oxidation behavior of the silicon nitride fibers produced by this method at high temperatures has rarely been reported before. Hence, the microstructures and the mechanical properties of $\mathrm{Si}_{3} \mathrm{~N}_{4}$ fibers before and after heat treatment in the air were investigated in detail, and the relationship between their microstructures and mechanical properties was also established.

\section{Experimental}

\subsection{Preparation of silicon nitride fibers and heat treatment}

PCS (average molecular weight $\approx 1500$, synthesized in our laboratory) was melt-spun into fibers at $300{ }^{\circ} \mathrm{C}$ in $\mathrm{N}_{2}$ with a lab scale 
melt-spinning apparatus. Bundles of PCS fibers were irradiated in He gas atmosphere by $2 \mathrm{MeV}$ electron beams, and the dose was 15 MGy with a dosing rate of around $1 \mathrm{kGy} \mathrm{s}^{-1}$. After irradiation, the fibers underwent heat treatment up to $400{ }^{\circ} \mathrm{C}$ with a heating rate of $5{ }^{\circ} \mathrm{C} \mathrm{min}^{-1}$. Then, the cured PCS fibers were set in an alumina tube furnace and heated up to $1000{ }^{\circ} \mathrm{C}$ in $\mathrm{NH}_{3}$ gas, followed by heat treatment under nitrogen gas $\left(\mathrm{N}_{2}\right)$ flow at a temperature of $1300{ }^{\circ} \mathrm{C}$, yielding silicon nitride fibers.

Before the heat treatment in air, original fibers were first desized at $600{ }^{\circ} \mathrm{C}$ for $1 \mathrm{~h}$ in air. Then, the heat treatment was carried out at a temperature range of $1000{ }^{\circ} \mathrm{C}-1400{ }^{\circ} \mathrm{C}$ for a dwell time of $2 \mathrm{~h}$ in the air in a box furnace under a pressure of $10^{5} \mathrm{~Pa}$.

\subsection{Characterizations}

The bulk composition of the silicon nitride fibers was determined by chemical analysis. Nitrogen and oxygen contents were determined using an N/O analyzer (EMGA-820, Horiba). From our previous experience, we know that the content of silicon can be obtained by the subtraction method since hydrogen was released from the precursor upon annealing at $1300{ }^{\circ} \mathrm{C}$. The surface morphology of the fibers was observed by a scanning electron microscope (SEM, Helios 600i FEI) equipped with an energy-dispersive X-ray spectroscopy. The crystalline state of the fibers was characterized by X-ray diffraction (XRD) analysis using a monochromatic $\mathrm{Cu} \mathrm{K} \alpha$ radiation with a D8 ADVANCE diffractometer (Bruker, Germany). The compositions of the fibers were traced by solid-state ${ }^{29} \mathrm{Si}$ NMR spectroscopy with a Varian Infinity Plus 300 spectrometer and X-ray photoelectron spectroscopy (XPS) analysis with a Thermo ESCALAB 250 apparatus using $\mathrm{Al} \mathrm{K} \alpha$ radiation with the energy of $1486.6 \mathrm{eV}$. TEM lamellas with a thickness $<100 \mathrm{~nm}$ were fabricated by the lift-out method in an FEI Helios 600i focused ion beam (FIB) system, and TEM imaging was performed using an FEI Tecnai F20 transmission electron microscope operating at $200 \mathrm{kV} .^{\mathbf{1 8 , 1 9}}$

In the present study, tensile tests were performed in ambient atmosphere on a universal material testing machine (Testometric, M3505CT) at a gauge length of $25 \mathrm{~mm}$ and an extension rate of $5 \mathrm{~mm} \mathrm{~min}{ }^{-1}$. Weibull modulus was calculated from 20 specimens for each heat-treated temperature.

\section{Results and discussion}

\subsection{Composition and microstructure of the untreated fibers}

The chemical composition analysis suggests that the main components of the ceramic fibers were $\mathrm{Si}, \mathrm{N}$, and $\mathrm{O}$. The general properties of the fibers are shown in Table 1 , and they have a molar composition of $\operatorname{SiN}_{1.27} \mathrm{O}_{0.09}$. Fig. 1 shows the elemental maps of the untreated fibers. The fiber was embedded in epoxy

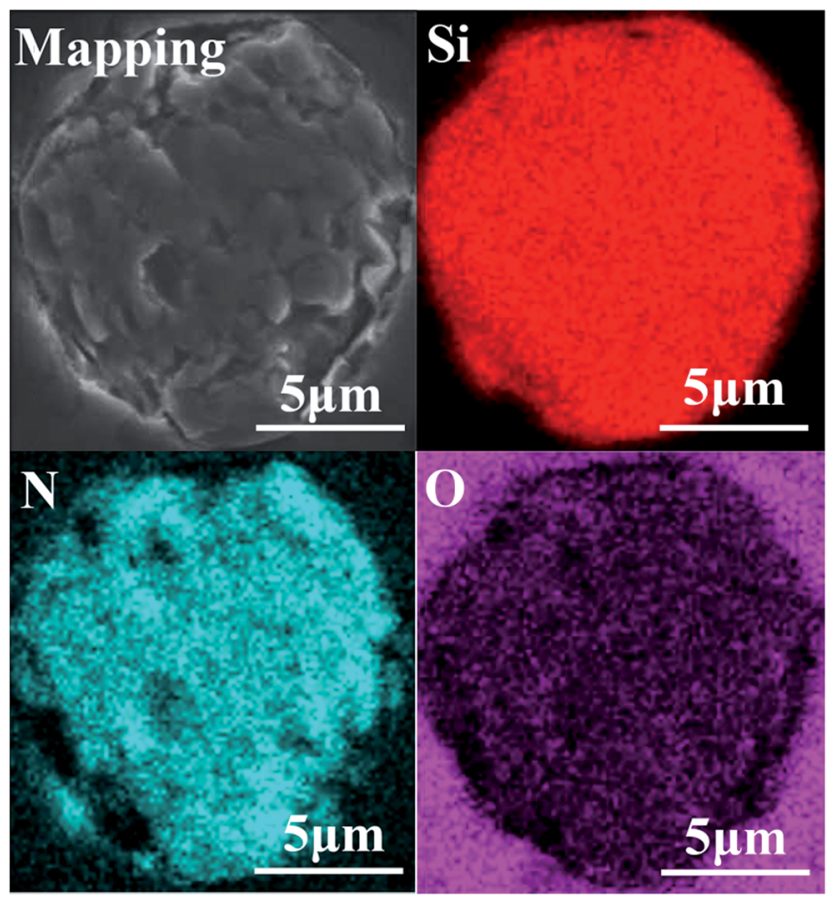

Fig. 1 Elemental distribution of the untreated fibers.

resin. Overall, the spatial distribution of $\mathrm{Si}, \mathrm{N}$ and $\mathrm{O}$ elements in the fiber was uniform.

Fig. 2 shows the external appearance of the desized silicon nitride fiber. Overall, the fibers exhibited a relatively uniform diameter of $12 \mu \mathrm{m}$ with smooth surfaces and rare defects. The fracture cross-section in Fig. 2(a) shows distinct mirror and hackle features, which are recognized as typical fracture traits of the ceramic fibers. Besides, no visible pores or defects were observed on the fracture surface in Fig. 2(b). From the results shown in Fig. 2(b) and 1, it can be seen that the fibers have high structural uniformity.

The crystalline state of the untreated fibers is shown in Fig. 3.

The XRD pattern of the untreated $\mathrm{Si}_{3} \mathrm{~N}_{4}$ fibers represents two broad diffraction peaks at around $23^{\circ}$ and $69^{\circ}$, revealing the amorphous nature of the fibers. A detailed microstructure was observed by high-resolution transmission electron microscopy (HR-TEM) in conjunction with selected-area electron diffraction (SAED). The HR-TEM revealed a homogeneous amorphous structure for the untreated fibers, while the diffraction pattern demonstrated a diffuse ring pattern, being a character of the microstructure with short-range order. This is consistent with the XRD result.

The most powerful technique by far to understand the chemical bonding in the ceramic fibers is NMR spectroscopy. A

Table 1 General properties of the untreated $\mathrm{Si}_{3} \mathrm{~N}_{4}$ fibers

\begin{tabular}{|c|c|c|c|c|c|c|c|}
\hline Properties & \multicolumn{3}{|c|}{ Element (wt\%) } & Density $\left(\mathrm{g} \mathrm{cm}^{-3}\right)$ & Diameter $(\mu \mathrm{m})$ & Strength (GPa) & Modulus (GPa) \\
\hline
\end{tabular}




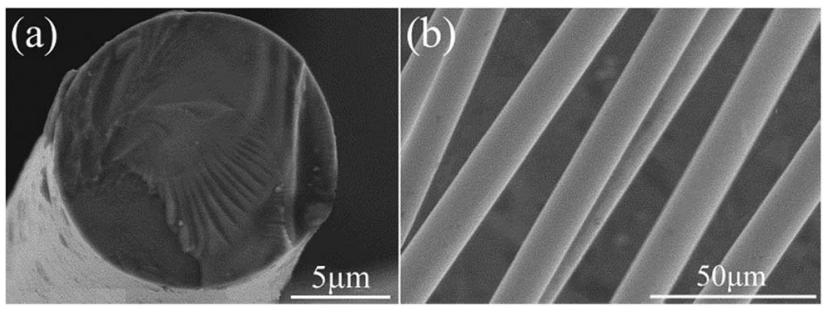

Fig. 2 SEM images of the untreated fibers.
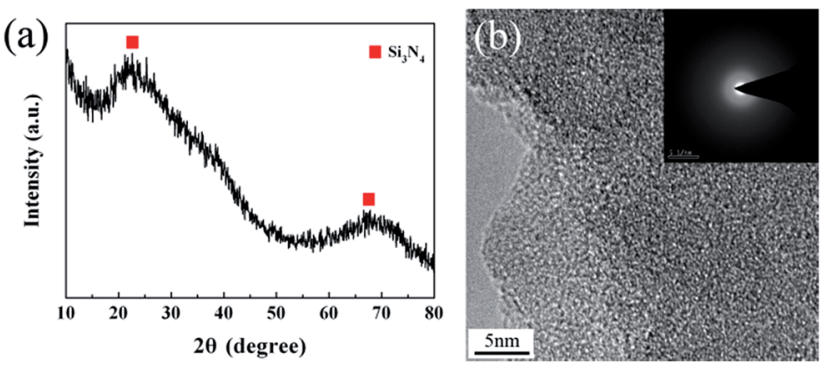

Fig. 3 (a) XRD spectrum and (b) TEM pattern of the untreated fibers.

${ }^{29} \mathrm{Si}$ NMR spectrum of the untreated fiber with a broad and continuous signal is shown in Fig. 4. It was noted that the strongest signal at $\delta=-49 \mathrm{ppm}$, representing the $\mathrm{Si}_{3} \mathrm{~N}_{4}$ structure, was close to the reported values $(\delta=-46 \mathrm{ppm})$ for amorphous $\mathrm{Si}_{3} \mathrm{~N}_{4}\left(\mathrm{a}-\mathrm{Si}_{3} \mathrm{~N}_{4}\right) .^{20}$ The result showed that the fiber was mostly composed of the amorphous $\mathrm{Si}_{3} \mathrm{~N}_{4}$ structure.

Besides, the surface chemical environment of the untreated fiber is investigated by XPS. Fig. 5 shows the overall XPS spectrum and the resolved high-resolution spectra of Si 2p, N 1s, C $1 \mathrm{~s}$, and $\mathrm{O} 1 \mathrm{~s}$ electrons. The $\mathrm{C} 1 \mathrm{~s}$ component could be assigned as the standard for calibration. Before being examined by XPS, the fiber was etched by $\mathrm{Ar}$ in order to eliminate the surface contaminants on the fiber surface. Hence, the Ar component might be introduced during the etching process. As shown in Fig. 5(b), there were three peaks in the Si 2p spectrum. The peak

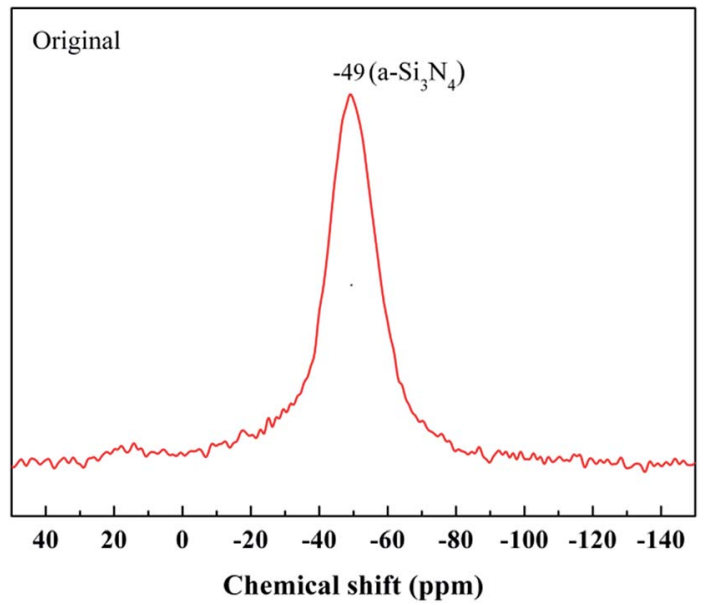

Fig. $4{ }^{29}$ Si NMR spectrum of the untreated fiber.
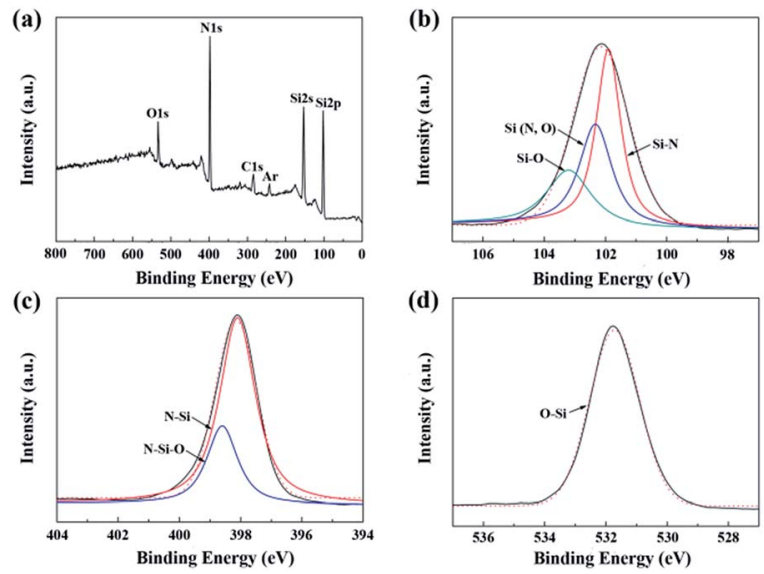

Fig. 5 XPS spectra of the untreated fibers: (a) overall spectrum; (b) Si $2 \mathrm{p}$; (c) N 1s; and (d) $O 1 \mathrm{~s}$.

located at $101.8 \mathrm{eV}$ can be attributed to the bond in $\mathrm{Si}_{3} \mathrm{~N}_{4}$. The other two peaks located at $102.2 \mathrm{eV}$ and $103.3 \mathrm{eV}$ were assigned to the $\mathrm{Si}-\mathrm{N}$ and $\mathrm{Si}-\mathrm{O}$ bonds in $\mathrm{Si}_{2} \mathrm{~N}_{2} \mathrm{O}$. The $\mathrm{Si}_{2} \mathrm{~N}_{2} \mathrm{O}$ phase, whose chemical structure is silicon atoms linked with both nitrogen and oxygen, was likely derived from the nitridation of the cured PCS fiber. ${ }^{21}$ Similarly, the peaks at $398.0 \mathrm{eV}$ and $398.6 \mathrm{eV}$ in the $\mathrm{N}$ 1s spectrum were assigned to the N-Si and N-Si-O bonds, respectively. Furthermore, the single peak at $532.2 \mathrm{eV}$ in the $\mathrm{O}$ 1s spectrum, which was shifted from $532.7 \mathrm{eV}$ of the standard $\mathrm{SiO}_{2}$, was attributed to the $\mathrm{O}-\mathrm{Si}$ bond in the $\mathrm{Si}-\mathrm{N}-\mathrm{O}$ structure. However, there was no $\mathrm{Si}-\mathrm{N}-\mathrm{O}$ structure observed in the above NMR spectrum. Thus, the content of $\mathrm{Si}-\mathrm{N}-\mathrm{O}$ structure may be too small to be able to be detected by NMR technique. Therefore, in conjunction with the NMR spectrum, it can be concluded that the fiber was composed of the amorphous $\mathrm{Si}_{3} \mathrm{~N}_{4}$ and $\mathrm{Si}_{2} \mathrm{~N}_{2} \mathrm{O}$ phase.

\subsection{Influence of heat treatment on microstructure and mechanical properties}

The XRD patterns of the untreated fibers after the heat treatment are shown in Fig. 6. It can be seen that the fibers retained their amorphous structure in the range of room temperature$1000{ }^{\circ} \mathrm{C}$. As the temperature increased, the degree of oxidation increased. Hence, the conspicuous cristobalite phase, which is one crystalline phase of $\mathrm{SiO}_{2}$, can be found in the XRD patterns when the treatment temperature exceeded $1200{ }^{\circ} \mathrm{C}$, demonstrating the sufficient oxidation of the fibers. Moreover, three main diffraction peaks at $22.0^{\circ}, 31.5^{\circ}$ and $36.1^{\circ}$, which were respectively assigned to the (101), (102) and (200) lattice planes of the cristobalite phase, presented in the XRD spectrum of the sample treated at $1200{ }^{\circ} \mathrm{C}$. Furthermore, the XRD peaks became sharper with the increase in the treatment temperature. The apparent crystallite sizes of cristobalite, which were calculated from the half-width value of three peaks above using Scherrer formula, are listed in Table 2. Obviously, the cristobalite grains grew into larger crystals with the increase in temperature and tended to grow rapidly at $1300{ }^{\circ} \mathrm{C}$, resulting in a strength degradation of the fiber, as discussed later in Section 3.3. 


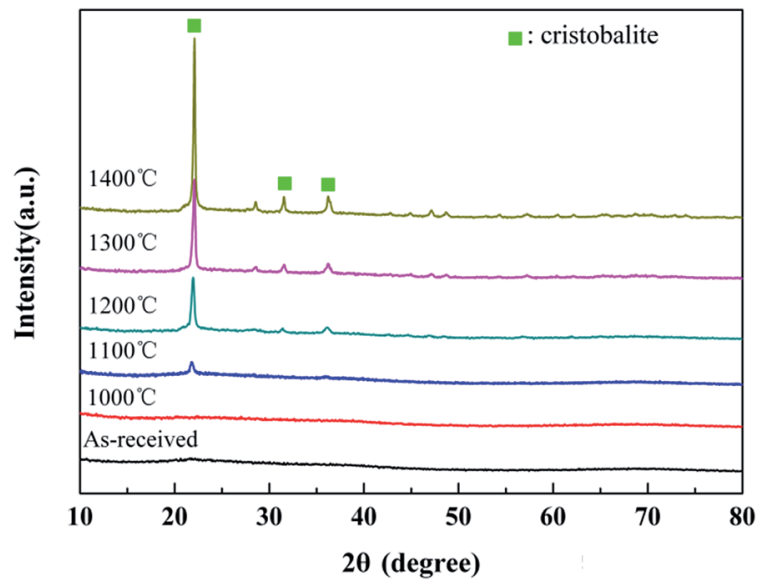

Fig. 6 XRD patterns of the untreated fibers after the heat treatment.

Table 2 Apparent crystallite sizes ( $D$ expressed in $\AA$ ) of the untreated fibers after the heat treatment obtained from XRD patterns

\begin{tabular}{llll}
\hline & $h k l$ & & \\
\cline { 2 - 4 } Temperature & $(101)$ & $(102)$ & $(200)$ \\
\hline $1200^{\circ} \mathrm{C}$ & 158 & 190 & 101 \\
$1300^{\circ} \mathrm{C}$ & 279 & 263 & 211 \\
$1400{ }^{\circ} \mathrm{C}$ & 335 & 297 & 233
\end{tabular}

The surface morphology of the untreated fibers after heat treatment is presented in Fig. 7. It can be found that the untreated fibers had relatively smooth and homogeneous surface, and this surface morphology was well retained even after the fibers were annealed at $1000{ }^{\circ} \mathrm{C}$. The fibers were subjected to a mild oxidation at $1100^{\circ} \mathrm{C}$ with a few crystalline grains on the surface. With temperature increasing up to $1200{ }^{\circ} \mathrm{C}$, it was found that the size of crystalline grains increased. The EDS result verified that the crystalline grains were $\mathrm{SiO}_{2}$ particles. As the temperature rose to $1300{ }^{\circ} \mathrm{C}$, some cracks appeared on the fiber surface which could cause damage to the fiber. When the treatment temperature was $1400{ }^{\circ} \mathrm{C}$, the gap between cracks increased with the expansion of the cracks.

The chemical composition of the fibers after the heat treatment is listed in Table 3. The weight ratio of $\mathrm{N}$ element in the fibers treated at $1400{ }^{\circ} \mathrm{C}$ was still $25.55 \%$. Compared to that of the untreated fiber $(37.85 \%)$, one can see that only a part of the fibers participated in the oxidation reaction. Hence, the changes in the composition and the structure of the fiber after the heat treatment at $1400{ }^{\circ} \mathrm{C}$ due to the oxidation were investigated by XPS and NMR. As shown in Fig. 8(a), the overall XPS spectrum of the fibers after the heat treatment at $1400{ }^{\circ} \mathrm{C}$ clearly revealed the presence of Si 2s, O 1s, C 1s, and Ar 2p electrons. Similarly, the $\mathrm{C} 1 \mathrm{~s}$ component could be assigned as the standard for calibration and the Ar component might be introduced during the etching process. In Fig. 8(b), the Si 2p spectrum with the peak centered at $103.5 \mathrm{eV}$ corresponded to the $\mathrm{Si}-\mathrm{O}$ bond, and the peak centered at $532.7 \mathrm{eV}$ in the $\mathrm{O} 1 \mathrm{~s}$ spectrum in

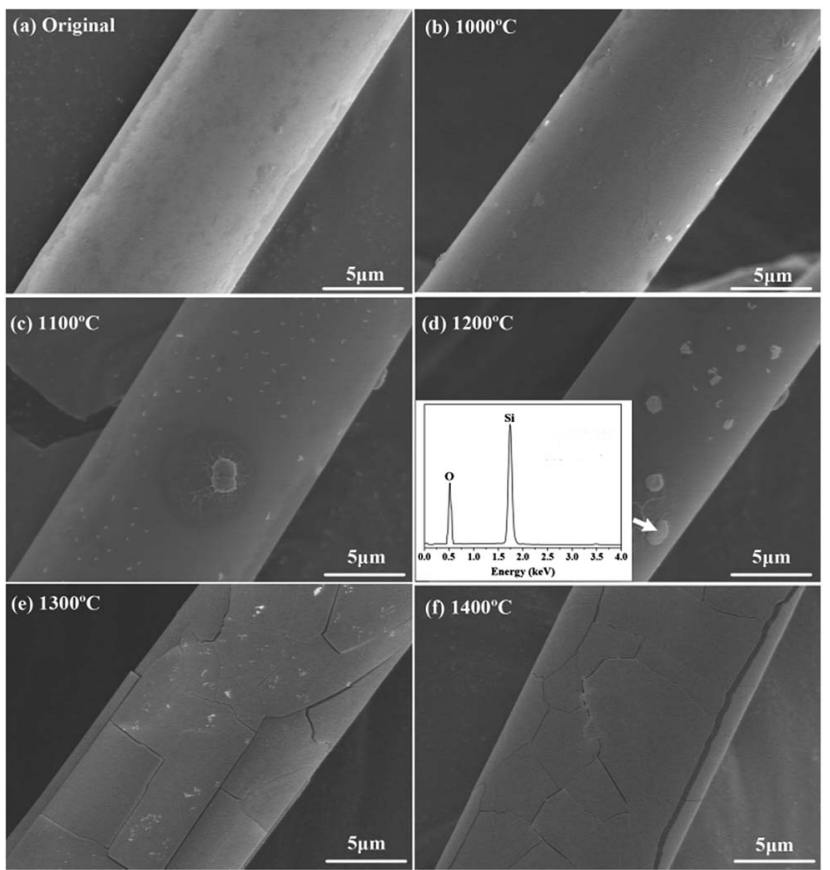

Fig. 7 Surface morphology of the untreated fibers before and after the heat treatment.

Table 3 Elemental compositions of the $\mathrm{Si}_{3} \mathrm{~N}_{4}$ fibers before and after the heat treatment

\begin{tabular}{|c|c|c|c|c|c|c|}
\hline \multirow[b]{2}{*}{ Samples } & \multicolumn{2}{|l|}{$\mathrm{Si}$} & \multicolumn{2}{|l|}{$\mathrm{N}$} & \multicolumn{2}{|l|}{$\mathrm{O}$} \\
\hline & wt $\%$ & at $\%$ & $\mathrm{wt} \%$ & at $\%$ & wt $\%$ & at $\%$ \\
\hline Untreated & 59.24 & 42.20 & 37.85 & 54.20 & 2.91 & 3.60 \\
\hline $1000{ }^{\circ} \mathrm{C}$ & 59.29 & 42.40 & 37.69 & 53.80 & 3.02 & 3.80 \\
\hline $1100{ }^{\circ} \mathrm{C}$ & 57.39 & 40.76 & 35.38 & 50.29 & 7.23 & 8.95 \\
\hline $1200^{\circ} \mathrm{C}$ & 57.41 & 41.12 & 31.62 & 45.11 & 10.97 & 13.77 \\
\hline $1300^{\circ} \mathrm{C}$ & 55.88 & 39.92 & 28.12 & 40.12 & 16.00 & 19.95 \\
\hline $1400^{\circ} \mathrm{C}$ & 55.32 & 39.56 & 25.55 & 39.46 & 19.13 & 20.98 \\
\hline
\end{tabular}

Fig. 8(c) was caused by the O-Si bond. ${ }^{22,23}$ Furthermore, the concentration of oxygen $(60.1 \mathrm{at} \%)$ at the surface was higher compared to the bulk concentration of oxygen (3.4 at\%), as determined by chemical analysis. Hence, the XPS spectra confirm that the oxidation layer was formed on the fiber surface. The ${ }^{29} \mathrm{Si}$ NMR spectrum of the fiber after the heat treatment at $1400{ }^{\circ} \mathrm{C}$ is shown in Fig. 9. It is noticed that the strong signal at $\delta=-49 \mathrm{ppm}$, representing the $\mathrm{Si}_{3} \mathrm{~N}_{4}$ structure, was the same as that in the ${ }^{29} \mathrm{Si}$ NMR spectrum shown in Fig. 4 of the untreated fiber. The signal at $\delta=-111 \mathrm{ppm}$, representing the $\mathrm{SiO}_{4}$ structure, showed that the fiber contained $\mathrm{SiO}_{2} \cdot{ }^{24,25}$ However, it should be noted that there was no $\mathrm{Si}-\mathrm{N}$ structure found in the above XPS spectra, which is probably due to the fact that the internal $\mathrm{Si}-\mathrm{N}$ structures were surrounded by the $\mathrm{SiO}_{2}$ oxidation layer.

In order to further study the microstructure of the fiber after the heat treatment at $1400{ }^{\circ} \mathrm{C}$, a cross-sectional thin foil was 

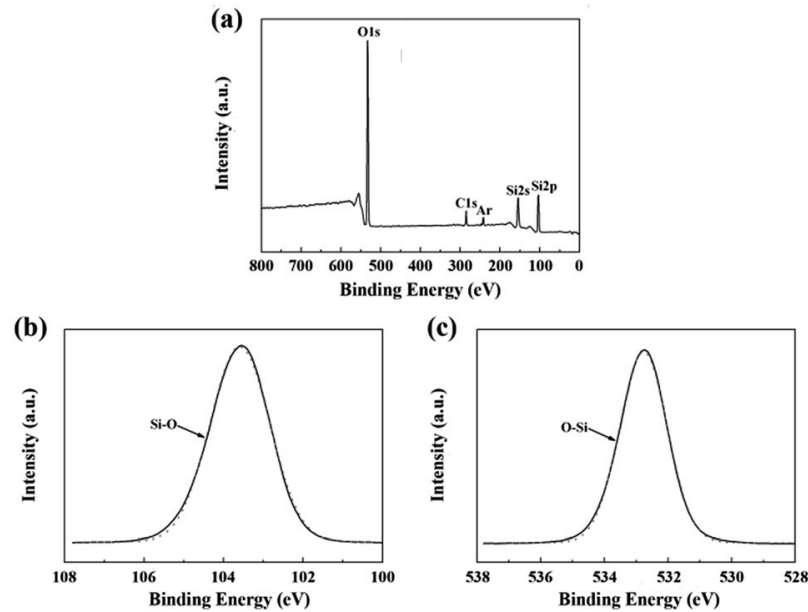

Fig. 8 XPS spectra of the fiber after the heat treatment at $1400^{\circ} \mathrm{C}$ : (a) overall spectrum; (b) Si 2p; and (c) $\bigcirc$ 1s.

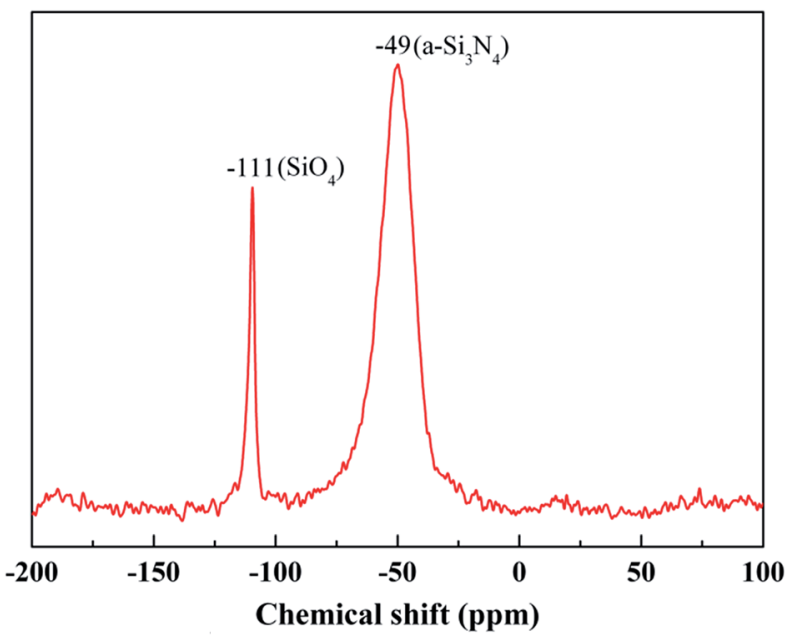

Fig. $9{ }^{29} \mathrm{Si}$ NMR spectrum of the fiber after the heat treatment at $1400^{\circ} \mathrm{C}$

extracted out of the fiber by FIB and then was characterized by bright field TEM (BF-TEM), high-resolution TEM (HR-TEM), and selected area electron diffraction (SAED). The results are shown in Fig. 10(a-e). A Cr layer, covering the thin foil surface, was utilized to increase the electrical conductivity of the fiber. Apparently, upon the heat treatment at $1400{ }^{\circ} \mathrm{C}$, a silica oxidation layer with a thickness $\sim 2 \mu \mathrm{m}$ covered the internal fiber, whose composition was further certified by EDS in Fig. 10(d and e). The Mo element, shown in EDS, resulted from a holder used to support the thin foil. Contrary to the internal fiber, the cover layer displayed a high degree of crystallinity, as evidenced by the HR-TEM images in Fig. 10(c). According to the experimental results, the oxidation of the fiber begins at the surface. With heat-treatment temperatures increasing, the inside fiber is oxidized. Consequently, the oxidation was uniformly performed from the outside in due to the amorphous state of the internal fiber. The result indicated that although the treatment
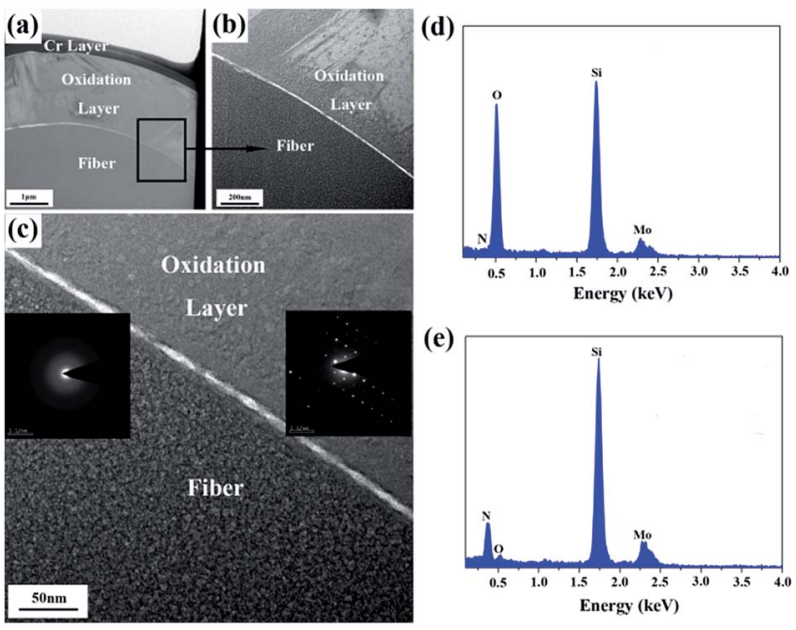

Fig. 10 (a) BF-TEM of the fiber after the heat treatment at $1400^{\circ} \mathrm{C}$; (b) magnified BF-TEM and (c) HR-TEM of the chosen region, the insets correspond to the SAED patterns; (d) EDS of the oxidation layer; and (e) EDS of the internal fiber.

temperature was up to $1400{ }^{\circ} \mathrm{C}$, only a part of the fiber participated in the oxidation reaction, and the silica oxidation layer was generated around the fiber surface due to the relatively short oxidation time.

According to the results above, the oxidation seemed to result from reactions (1) and (2) of $\mathrm{Si}_{3} \mathrm{~N}_{4}$ and $\mathrm{Si}_{2} \mathrm{~N}_{2} \mathrm{O} .^{26}$

$$
\begin{gathered}
\mathrm{Si}_{3} \mathrm{~N}_{4}(\mathrm{~s})+3 \mathrm{O}_{2}(\mathrm{~g}) \rightarrow 3 \mathrm{SiO}_{2}(\mathrm{~s})+2 \mathrm{~N}_{2}(\mathrm{~g}) \\
\Delta_{\mathrm{r}} G^{\theta}=\left[-1859 \times 10^{3}+268.6 T\right] \mathrm{J} \mathrm{mol}^{-1} \\
\mathrm{Si}_{2} \mathrm{~N}_{2} \mathrm{O}(\mathrm{s})+3 / 2 \mathrm{O}_{2}(\mathrm{~g}) \rightarrow 2 \mathrm{SiO}_{2}(\mathrm{~s})+\mathrm{N}_{2}(\mathrm{~g}) \\
\Delta_{\mathrm{r}} G^{\theta}=\left[-843.3 \times 10^{3}+154.3 T\right] \mathrm{J} \mathrm{mol}^{-1}
\end{gathered}
$$

Using thermodynamic data of the reactions (1) and (2), we can calculate $\Delta_{\mathrm{r}} G^{\theta}\left(\mathrm{J} \mathrm{mol}^{-1}\right)<0$ in the temperature range of 1000-1400 ${ }^{\circ} \mathrm{C}$. Hence, $\mathrm{Si}_{3} \mathrm{~N}_{4}$ and $\mathrm{Si}_{2} \mathrm{~N}_{2} \mathrm{O}$ can react with oxygen to produce $\mathrm{SiO}_{2}$, resulting in a weight gain. Hence, theoretically with the temperature increasing continuously, a dense outer oxide layer will be formed around the fiber and protect the internal fiber from further oxidation. However, in practice, as the oxidation reaction progresses, nitrogen released by the oxidation reaction continuously will blow up the dense outer oxide layer and generate cracks. Under these conditions, the micro-cracked oxide layer cannot protect the fiber and allows fast oxygen diffusion to the interface, resulting in a dramatic increase in the oxidation rate. A tentative schematic, describing the oxidation process, is illustrated in Fig. 11. Fig. 11(a) showed the oxidation reaction initiated at the fiber surface, corresponding to the observation on the fibers treated at the temperature of $1100{ }^{\circ} \mathrm{C}$ and $1200{ }^{\circ} \mathrm{C}$ as shown in Fig. $7(\mathrm{c})$ and (d). Finally, as shown in Fig. 11(b), $\mathrm{N}_{2}$ diffusion outwards through the oxide layer resulted in the formation of cracks on the fiber surface, corresponding to the phenomena observed in Fig. 7(e) and (f). 

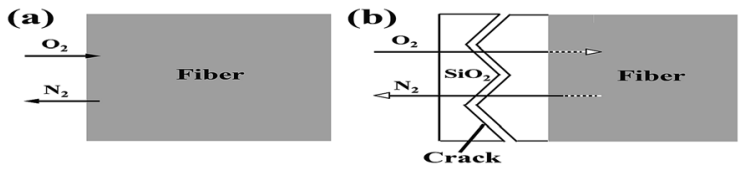

Fig. 11 Tentative schematic description of the oxidation of silicon nitride fibers showing the mass transfer at reactant/product interface: (a) $1100{ }^{\circ} \mathrm{C}-1200^{\circ} \mathrm{C}$ and (b) $1300-1400{ }^{\circ} \mathrm{C}$.

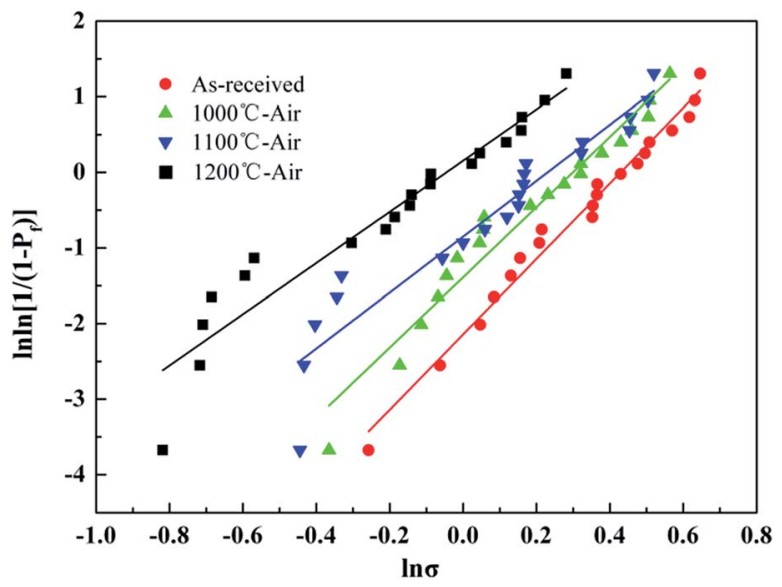

Fig. 12 Weibull plots for the fiber tested before and after the heat treatment.

\subsection{Influence of heat treatment on the mechanical property of $\mathrm{Si}_{3} \mathrm{~N}_{4}$ fiber}

In order to evaluate the influence of heat treatment on the mechanical properties of the $\mathrm{Si}_{3} \mathrm{~N}_{4}$ fibers, the single filament tensile strength of the untreated fibers and those after the heat treatment was measured at room temperature. ${ }^{27}$ In this study, Weibull statistical model, which is commonly used for characterization of brittle materials, was used to characterize the tensile strength of the individual fiber. In this model, the failure probability $P_{\mathrm{f}}$ is estimated by eqn (3), where $\sigma$ is the fracture strength, and $\sigma_{0}$ and $m$ are the Weibull parameters, i.e. the scale parameter and the Weibull modulus, respectively. It is wellknown that a larger $m$ will lead to a steeper function and then a lower dispersion of tensile strength.

$$
P_{\mathrm{f}}(V)=1-\exp \left[-\left(\sigma / \sigma_{0}\right)^{m}\right]
$$

Taking the logarithm of eqn (3) twice gave a linear equation, eqn (4), with a slope equal to $m$ and a $y$-intercept equal to $-m \ln \sigma_{0}$.

$$
\ln \ln \left[1 /\left(1-P_{\mathrm{f}}\right)\right]=m \ln \sigma-m \ln \sigma_{0}
$$

The $\sigma$ values were the experimental tensile stresses. The test results were converted into an experimental probability distribution. This was done by ordering the results from the lowest to the highest rupture stress, which means $\sigma_{1}<\sigma_{2}<\ldots<\sigma_{i} \ldots<$ $\sigma_{N-1}<\sigma_{N}$ (N was the sample number). Since the true value of $P_{\mathrm{fi}}$ for each $\sigma_{i}$ was unknown, it had to be estimated. According to
Table 4 Weibull parameters of the single fiber tensile test of the heattreated fibers

\begin{tabular}{lllll}
$\begin{array}{l}\text { Temperature } \\
\left({ }^{\circ} \mathrm{C}\right)\end{array}$ & $\begin{array}{l}\text { Weibull } \\
\text { modulus }\end{array}$ & $\begin{array}{l}\text { Scale parameter } \\
(\mathrm{GPa})\end{array}$ & $\begin{array}{l}\text { Tensile strength } \\
(\mathrm{GPa})\end{array}$ & $\begin{array}{l}\text { Retention } \\
(\%)\end{array}$ \\
\hline Untreated & 4.99 & 1.84 & 1.81 & - \\
1000 & 4.65 & 1.55 & 1.57 & 87.23 \\
1100 & 3.69 & 1.16 & 1.08 & 60.24 \\
1200 & 3.39 & 0.96 & 0.91 & 50.29
\end{tabular}

Riccardi, ${ }^{28}$ when $N \geq 20, P_{\mathrm{f}}$ was in non-weighted analysis and could be defined as following (eqn (5)).

$$
P_{\text {fi }}=(i-0.5) / N
$$

The Weibull plots of the untreated fibers before and after the heat treatment were summarized in Fig. 12, and the Weibull parameters of the individual fiber tensile test are listed in Table 4. As mentioned before, a bigger $m$ value means a lower dispersion of tensile strength. The Weibull modulus decreased from 4.99 to 3.39 with the temperature increasing up to $1200^{\circ} \mathrm{C}$, which indicated that the dispersion of the tested tensile increased indistinctively with temperature. It was necessary to note that the Weibull statistics of the fibers after the heat treatment at $1300{ }^{\circ} \mathrm{C}$ and $1400{ }^{\circ} \mathrm{C}$ were not provided in this study because the fibers after the heat treatment at those temperatures were too brittle to prepare enough fiber samples for testing.

As can be seen in Table 4, the fiber possessed a comparatively high tensile strength due to its excellent heat resistance when the treatment temperature was below $1200^{\circ} \mathrm{C}$. Although the tensile strength of the fiber decreased to $0.86 \mathrm{GPa}$ after the heat treatment at $1200{ }^{\circ} \mathrm{C}$, the strength retention was still about $50 \%$. Such strength loss after high-temperature exposure was mainly attributed to the oxidation of silicon nitride as shown in Fig. 6. In conclusion, the silicon nitride fibers could be used in the air at a temperature lower than $1200^{\circ} \mathrm{C}$ without considering some other factors, such as vapor, pressure, and serving time.

In general, the strength degradation of silicon nitride fibers after the heat treatment is believed to result from the flaw size on the fiber surface as well as the inside during the heat treatment because the mechanical properties of a brittle material are under control of the flaw. According to the research by Taylor, ${ }^{29}$ there is a relationship existing between the flaw type and the tensile strength of the fibers. The tensile strength of the fibers can remain 1.0-2.0 GPa with a few internal flaws and, in contrast, the tensile strength of the fibers decreases to 0.6$0.9 \mathrm{GPa}$ with a rough surface, such as particles, holes, or cracks.

As shown in Fig. 7 and Table 4, the change of the internal flaw size resulted in the strength degradation of silicon nitride fibers after the heat treatment at $1000{ }^{\circ} \mathrm{C}$. With the temperature increasing up to $1100^{\circ} \mathrm{C}$ and $1200^{\circ} \mathrm{C}$, the strength degradation of silicon nitride fibers was dominated by the presence of $\mathrm{SiO}_{2}$ particles, which were derived from the oxidation reaction, on 
the fiber surface. When the temperature increased to $1300{ }^{\circ} \mathrm{C}$, an oxide layer consisting mainly of pure silica was formed on the fiber surface, leading to the brittleness of the fiber. Consequently, the fiber had no tensile strength after the treatment at $1300{ }^{\circ} \mathrm{C}$ and $1400{ }^{\circ} \mathrm{C}$.

\section{Conclusions}

The microstructure and the mechanical properties of silicon nitride fibers have been investigated before and after the heat treatment at elevated temperature in air. Microstructural analysis shows that the fibers are composed of amorphous silicon nitride and a few $\mathrm{Si}_{2} \mathrm{~N}_{2} \mathrm{O}$ phases. The heat treatments above $1100{ }^{\circ} \mathrm{C}$ provoked the oxidation reaction from silicon nitride to silicon dioxide and the cracks, which were derived from the gas emission during the oxidation reaction with the temperature increasing to $1300{ }^{\circ} \mathrm{C}$, were formed on the fiber surface. Ultimately, an oxidation layer with a thickness of $\sim 2 \mu \mathrm{m}$ formed on the fiber surface upon the heat treatment at $1400{ }^{\circ} \mathrm{C}$, which indicated that the fiber was not completely oxidized. This change was accompanied by a fall in the tensile strength of the individual fiber at room temperature. The relatively lower strength degradation indicates that the fiber would possess a high serving life at a serving temperature lower than $1200{ }^{\circ} \mathrm{C}$. It demonstrates an excellent thermal resistance, which can be useful for a potential application in the ceramic matrix composites in the air environment.

\section{Conflicts of interest}

There are no conflicts to declare.

\section{Acknowledgements}

The authors appreciate the financial support from the National Natural Science Foundation of China (51202291), the Aid Program for Innovative Group of National University of Defense Technology, and the Aid program for Science and Technology Innovative Research Team in Higher Educational Institutions of Hunan Province.

\section{Notes and references}

1 M. Sato and K. Okamura, J. Ceram. Soc. Jpn., 1998, 106, 248255.

2 V. Pavarajarn, R. Precharyutasin and P. Praserthdam, J. Am. Ceram. Soc., 2010, 93, 973-979.
3 C. Shi, Y. Zhu and H. Qian, Mater. Res. Bull., 2014, 51, 161166.

4 A. L. Hector, Coord. Chem. Rev., 2016, 323, 120-127.

5 G. X. Zhu, S. M. Dong and D. W. Ni, RSC Adv., 2016, 6, 8348283492.

6 S. Kamimura, T. Seguchi and K. Okamura, Radiat. Phys. Chem., 1999, 54, 575-581.

7 D. Mocaer, R. Pailler and R. Naslain, J. Mater. Sci., 1993, 28, 2639-2653.

8 N. Bansal and M. Dickerson, Mater. Sci. Eng., A, 1997, 22, 149-157.

9 O. Delverdier and M. Monthioux, J. Eur. Ceram. Soc., 1994, 14, 313-325.

10 K. Sato, H. Kakisawa and Y. Kagawa, J. Mater. Sci. Lett., 2000, 19, 1179-1183.

11 X. Zhao, K. Han and Y. Peng, Mater. Lett., 2011, 65, 27172720.

12 G. S. Bibbo, P. M. Benson and C. G. Pantano, J. Mater. Sci., 1991, 26, 5075-5080.

13 E. Bouillon, D. Mocaer and J. F. Villeneuve, J. Mater. Sci., 1991, 26, 1517-1530.

14 T. Seguchi, Radiat. Phys. Chem., 2000, 57, 367-371.

15 M. Sugimoto, T. Shimoo and K. Okamura, J. Am. Ceram. Soc., 1995, 78, 1013-1017.

16 G. Chollon, J. Eur. Ceram. Soc., 2000, 20, 1959-1974.

17 H. T. Liu, L. W. Yang and X. Sun, Carbon, 2016, 109, 435-443.

18 K. Okamura, M. Sato and Y. Hasegawa, Ceram. Int., 1987, 13, 55-61.

19 X. S. Zhang, L. W. Yang and H. T. Liu, $R S C A d v .$, 2017, 7, 23334-23341.

20 M. K. Cinibulk, G. Thomas and S. M. Johnson, J. Am. Ceram. Soc., 1992, 75, 2044-2049.

21 X. Hu, C. W. Shao and J. Wang, J. Mater. Sci., 2017, 52, 75557566.

22 F. Porz and F. Thommler, J. Mater. Sci., 1984, 19, 1283-1295.

23 S. Ichimura, K. Koike and A. Kurokawa, Surf. Interface Anal., 2000, 30, 497-501.

24 F. Liu, L. Qiu and L. Zhao, Chem, 2006, 69, 393-398.

25 M. Casu, A. Lai and A. Musinu, J. Mater. Sci., 2001, 36, 37313735 .

26 F. F. Lange, J. Am. Ceram. Soc., 1978, 61, 53-56.

27 Y. Wang and H. F. Cheng, Mater. Sci. Eng., A, 2013, 578, 287293.

28 C. C. Riccardi and C. I. Vallo, Polym. Eng. Sci., 2002, 42, 12601273.

29 S. T. Taylor, Y. T. Zhu and W. R. Blumenthal, J. Mater. Sci., 1998, 33, 1465-1473. 